\title{
UCLA
}

Mester

Title

Ultimo verano

Permalink

https://escholarship.org/uc/item/1fg1t1zb

Journal

Mester, 1(0)

Author

Ayuso, Emilio M.

\section{Publication Date}

1970

\section{DOI}

10.5070/M310021285

\section{Copyright Information}

Copyright 1970 by the author(s). All rights reserved unless otherwise indicated. Contact the author(s) for any necessary permissions. Learn more at https://escholarship.org/terms

Peer reviewed 


\section{Ultimo verano}

En la casa, un día sin lluvia

Oscura, cubiertas echadas, las cortinas firmes,

Taburete, silla, junto a la ventana ...

Una, dos, tres, cuatro colillas . . .

Mozart, no, Beethoven, no, Bach

Sí, Bach, la partitura, una hoja.

Tabacalera Española, S.A. . .

Sepias de labios ausentes;

La mano las juega.

Hojas de Apollinaire ruedan

El tren castellano no aporta consuelo

Imposibles las horas del campo

Otra vez allí .... hoy viento

Luz, Bach, no, Brahms, no . . .

Tan, tan, niebla, ahora niebla.

La mano las juega. . .

Una, dos, tres ... las muerde

Y también la cuarta

TABAC ....., S.A. 